\title{
Tibetan Medical Paradigms for the SARS-CoV-2 Pandemic
}

\section{Understanding coVID-19, Microbiome Links, and Its Sowa Rigpa Nosology}

\author{
Tawni Tidwell | ORCID: 0000-0001-9358-9958 \\ Center for Healthy Minds, University of Wisconsin-Madison, Madison, \\ WI, USA \\ ttidwell@wisc.edu
}

Khenrab Gyamtso

Tibetan Traditional Herbal Centre, Gangjong Choedenling, Toronto, Canada khenrabg@gmail.com

\begin{abstract}
As prophesized in early Tibetan medical works, the emergence of a pathogen such as SARS-CoV-2 that could inflict such a virulent infectious disease such as COVID-19 provided conditions for an expected yet alarming new phenomenon to threaten the health of inhabitants on the Tibetan Plateau. As SARS-CoV-2 spread into a global pandemic, Tibetan physicians worldwide engaged in symposiums, conferences, and clinical exchanges to situate the virus and its disease within Tibetan medical nosology. They sought to reconcile prophesies of global impact and develop critical treatment protocols for their communities. This article presents this particular perspective on COVID-19 as discussed among Tibetan medical colleagues in early April 2020, with follow-up discussions a year later. It introduces the disease's nosology as a specific type of virulent infection (gnyan rims), and describes the etiology, diagnosis, and treatment as explicated in the Tibetan classic Four Medical Treatises and related commentaries. As Tibetan physicians gain attention for their treatments of mild- and medium-severity CoviD-19 cases, understanding the Tibetan medical paradigm for the condition highlights distinctions of therapeutic and investigative relevance compared to biomedical and other traditional Asian medical approaches.
\end{abstract}

\section{Keywords}

SARS-CoV-2 - COVID-19 - Sowa Rigpa - biomedicine - microbiome - etiology 


\section{Introduction}

As predicted more than a thousand years ago, today we are encountering the prophesies of a degenerate era when hitherto unknown infectious disease, toxins, and environmental devastation and suffering is occurring. It is time to revisit the wisdom of our medical canon and cultivate the practices so critical at this time-compassion, wisdom, and the wish for all to be relieved from suffering. ${ }^{1}$

This assessment of the socioecological conditions that gave rise to the novel coronavirus SARS-CoV-2 as understood by the Tibetan medical tradition was described in the initial weeks of the outbreak by Tibetan medical physician Dr. Khenrab Gyamtso accompanied by his colleague and Johns Hopkins epidemiologist Dr. Konchok Dorjé in their joint interview with Radio Free Asia. At a coincident time, Dr. Lobsang Dhondup and Dr. Tashi Rabten, two Tibetan physicians residing in the United States, voiced a similar perspective in a think piece for a Tibetan online news site:

The root cause of these epidemics is greed. The insatiable desire to eat varieties of foods that we should not eat, to kill animals mindlessly, destroy the environment [for personal gain], and amass consumption [insatiably]. We have created severe imbalance in our world, and our ethics and compassion have deteriorated. ${ }^{2}$

In the months prior, colleagues on the Tibetan Plateau had articulated similar assessments. $^{3}$

Such accounts may seem odd to a general public accustomed to the Euroamerican tradition of biomedicine in which prognostic medical futures are not conceived let alone theorized, and global behaviors are rarely connected to healthcare crises. The Tibetan medical tradition, known as Böluk Sowa Rigpa (Bod lugs gso ba rig pa) in Tibetan, ${ }^{4}$ or the "Tibetan System of Healing Knowledge," integrally tracks individual- and societal-level behaviors

1 Bstan 'dzin dbang phyugs 2020 (transcribed and translated by the authors).

2 Blo bzang don grub and Bkra shis rab brtan 2020. The original article is in Tibetan; all translations are the authors' own unless otherwise noted.

3 Tidwell 202ob. For a compilation of related research published thereafter, see Dmig mar che ba 2020 ; Yum ba 2020.

4 All italicized terms are Tibetan unless otherwise noted. Tibetan terms are written in standard phonetic conversion as provided by Germano and Tournadre 2010, followed by the Tibetan spelling transliteration as devised by Wylie 1959 . 
as consequent to life-course health outcomes and experiences. The medical tradition likewise has served a large region of Asia with primary healthcare for several hundred years, ${ }^{5}$ with clinics even today outnumbering biomedical clinics at every administrative level across an area the size of Europe. ${ }^{6}$ Various contemporary sources refer to the medical tradition simply as Sowa Rigpa (Gso ba rig pa), or the "Knowledge Field of Healing." Its related contemplative practices have gained foremost attention from biomedical research communities for their contributions to health and well-being. ${ }^{7}$ Furthermore, pharmacological research on its formulas have demonstrated a wide range of biological activities, including antimalarial, ${ }^{8}$ anticancer, ${ }^{9}$ antimicrobial, ${ }^{10}$ antiviral, ${ }^{11}$ vascular- and neuroprotective, ${ }^{12}$ and immune and inflammation modulatory, ${ }^{13}$ through multicompound, multitarget pleiotropic signatures. ${ }^{14}$ Formulas specific to the respiratory tract with antibacterial properties have also been studied..$^{15}$ Such work illustrates the relevance of this several thousandyear-old tradition in contemporary times-even for a condition of pandemic scale as one of our greatest modern global health crises.

As the novel coronavirus spread across China, two of the largest Tibetan regions on the Tibetan Plateau announced its first cases-in Qinghai Province and the Tibetan Autonomous Region. Tibetan physicians began preparing treatments for patients infected with a disease perhaps unprecedented in Tibetan history despite prescience in classical texts. SARS, severe acute respiratory syndrome, incited an initial major wave of epidemic-level clinical preparations during the 2003 eight-month outbreak with 8,100 cases reported. ${ }^{16}$ Though none arrived in Tibet, Tibetan physicians demonstrated an armament of medical and ritual approaches in their repertoire that would be enacted should the virus arrive. The Ebola virus breakout from 2014 to 2016 in West Africa-the largest, most complex Ebola outbreak since its discovery in 1976 - motivated

Byams pa 'phrin las 2004 .

Tidwell 2020b.

Lutz et al. 2008; Kaliman et al. 2014; Rosenkranz et al. 2016.

Wangchuk et al. 2012, 2013.

Jenny et al. 2005; Choedon et al. 2006, 2011, 2014; Zhao et al. 2018.

Wangchuk et al. 2018.

Sangmo et al. 2007 .

Korwin-Piotrowska et al. 1992; Split et al. 1998; Exner et al. 20o6; Melzer et al. 2006.

Vennos, Melzer, and Saller 2013; Wangchuk et al. 2011, 2018.

Schwabl and van der Valk 2019. For systematic reviews of related clinical research, see Reuter, Weißhuhn, and Witt 2013; Luo et al. 2015. For analyses of collaborative pharmacological research approaches, see Tidwell and Nettles 2019.

Jankowski et al. 1991.

Craig and Adams 2008. 
another surge of preparations among the Tibetan medical community as they faced the reality of frequent human transit between West Africa and China stemming from tight business and aid relations, and its potential pandemic threat. In this latter outbreak, physicians at the foremost Tibetan medical hospital in eastern Tibet, Qinghai Provincial Tibetan Medical Hospital, began revisiting key passages of root texts, and key formulas indicated as part of a prophesied repertoire needed for this era of unprecedented infectious disease and environmental toxins. The Tibetan medical classic, the Four Medical Treatises (Rgyud bzhi), with described antecedents originating as early as the seventh century CE and the current composition formalized in the twelfth century, is the foundational text informing both the theory and practice of Tibetan medicine. Along with elaborations in its most prominent commentaries, ${ }^{17}$ it predicts a time when hitherto unencountered toxins and infectious diseases appear due to harm inflicted on the environment and resulting imbalances. The novel coronavirus that began its outbreak in December 2019 motivated the next iteration of Tibetan medical preparations revisiting prognosticated forms of pandemic treatments. Globally, SARS-CoV-2 has taken far more lives than the Ebola virus and SARs outbreaks combined. ${ }^{18}$ Though only a couple hundred confirmed cases occurred on the Tibetan Plateau in mid-February 2020, the virus has now affected nearly every Tibetan community globally, including the first US Covid-19 epicenter in Queens, New York, one of the densest Tibetan communities outside Tibet and India. ${ }^{19}$ During this time, these communities have turned predominantly to Tibetan medicine for their therapeutic refuge.

This recent epidemic has exemplified a new degree of clinical proficiency amid a global crisis. Tibetan physicians led successful health education

17 Prominent for the discussion here are Skyem pa tshe dbang 200o; Zur mkhar pa blo gros rgyal po 1989; De'u dmar bstan 'dzin phun tshogs 2009; Sangs rgyas rgya mtsho 1994, 2005; Kong sprul yon tan rgya mtsho 2005; Khro ru tshe rnam rin po che 2003. For discussion on other sources for gnyan nad and rims nad, see Dmig mar che ba 202O; Yum ba 2020. For a review of related medical literature from the tenth to fifteenth centuries $\mathrm{CE}$, see Simioli 2019 on the Great Vase of the Amrta of Immortality ('Chi med bdud rtsi bum chen; Slob dpon pad ma 'byung gnas 2006) and its redaction by Jamgön Kongtrül ('Jam mgon kong sprul blo gros mtha' yas, 1813-99) and Jamyang Khyentse Wangpo ('Jam dbyangs mkhyen brtse'i dbang po, 1820-92); the Moon King (Zla ba'i rgyal po; Phags pa klu sgrub 1989), which predates the Four Medical Treatises; the Sons'Benefit (Bu don ma; G.yu thog yon tan mgon po 2009), which is an ancillary treatise ascribed to Yutok Yönten Gönpo; and the Tibetan translation of Compendium of the Essence of the Eight Branches (Yan lag brgyad pa'i snying po bsdus pa; Skt. Aștāangahṛdayasaṃhitā;), an Āyurveda classic authored by Vāgbhața (Pha khol 2005).

18 MacIntyre and Chughtai 2016; Petersen et al. 2020.

19 See Craig et al. 2021, in this volume. 
campaigns, effective treatment protocols, and nuanced scholastic discourse, reviving previously textually ensconced directives targeting such virulent infectious disease. ${ }^{20}$ This article will highlight key sections from the Tibetan medical classics that framed discussions and exchanges of Tibetan medical physicians during the pandemic to present: (I) the grounded theory of this class of infectious diseases as nyenrim (gnyan rims); ${ }^{21}$ (II) the related causal factors, inciting conditions, and modes of infection for epidemic-level disease; (III) the specific characteristics, natures, and types of virulent (gryan) diseases and their related pathogens (gnyan srin); (IV) preventative measures for and diagnostic signs of nyenrim; and (v) treatment approaches for virulent conditions (gnyan nad) of epidemic scale. In framing this discussion, we look at conceptual paradigms related to biomedical understandings of microbes and similarities in their relationships related to the microbiome.

\section{Grounded Theory for Identifying COVID-19 as Nyenrim}

In Tibetan medicine generally, epidemic-level infectious disease including many viral conditions are described by the nosological category called rim illness (rims nad), and specifically, nyenrim. The pathology related to these conditions sits within a larger Sowa Rigpa medical paradigm of minute organisms called sinbu (srin bu). Sinbu are understood to permeate the environment as well as our bodies. They have important functional roles in health and, in imbalance and dysfunction, drive disease processes. Rim illnesses are a group of conditions that occur when harmful classes of sinbu enter the body due to their infectious nature and drive disease processes characterized by fever, sweats, and various other symptom profiles ranging from gastrointestinal distress, lung infections, poor quality blood, headaches, and heart arrhythmias.

\section{Sinbu, an Endemic Concept for Microorganisms and a Sowa Rigpa Microbiome}

The earliest appearance of the sinbu concept appears in a collection of translated discourses attributed to the Buddha called the Kangyur $(B k a$ ' gyur $) .{ }^{22}$ In

\footnotetext{
$20 \quad$ Tidwell 202ob.

21 For gnyan rims, instead of the Wylie transliteration, we will use the standard phonetics of nyenrim.

22 The translation of Buddhist texts from other languages such as Sanskrit and Pāli into Tibetan began in the seventh century CE (Harrison 1996). Analyzing the appearance of a cognate term for srin bu in the Pāli canon, the most complete extant early Buddhist canon, is beyond the scope of this article. The cognate term rākșasa in Ayurveda has a
} 
the Vinaya section on monastic discipline, there are thousands of instances of the term $\sin (\sin ) .{ }^{23}$ One story relates,

Three thousand years ago, in an era absent of many external supporting conditions, the number of sinbu in the body outnumbered the number of cells. In total, the coexistent sinbu in the body numbered eighty thousand with each sinbu type numbering several thousand. Since the sinbu outnumbered the body's aggregates, it was called the sin's aggregate. ${ }^{24}$

In a later passage, it also points to the role of sinbu in manifesting cognitiveaffective factors, such that in the body of Subhūti, a great bodhisattva and one of the Buddha's principal disciples, the eighty thousand types of sinbu did not exist because a completely purified mind and completely purified speech lead to the attainment of a completely purified body. ${ }^{25}$

Assessing medically-related content in the Kangyur, ${ }^{26}$ there are several distinct sections that describe sinbu, including passages characterizing sinbu in our body, how the coemergent sinbu community develops in our body from birth, the functional and dysfunctional physiological roles of our embodied sinbu, enumerated classes of sinbu coexistent with our bodies, and related approaches to cultivating wellness and healing. For example, one passage states:

By seven days after emerging from the womb at birth, over eighty thousand types of sinbu will have developed within the body. Those sinbu

similar connotation, and thus, presumably also in the Sanskrit canon of discourses attributed to the Buddha, which similarly influenced the development of Ayurveda (Zysk 1991, 1993). Several other terms for "invisible" microorganisms exist that can contaminate food and environments and cause sickness. These include: krimi, vaikārika (krimi), ägantuja, rākșasa, bhüta, and piśāca (Saini and Porte 2015). However, due to the integrity with which translations were completed of these scriptures, it is possible that the earliest instance of this concept appearing in written form dates to as early as $29 \mathrm{BCE}$, when the first texts appeared 454 years after the death of the historical Buddha; however, extant texts have not been found (Drewes 2015, 131). Some of these texts were later translated into Chinese in the fourth century $\mathrm{CE}$, and the earliest textual fragments of canonical Pāli were discovered in Burma and date only to mid-fifth and mid-sixth century CE (Stargardt 2000, 25). Searches conducted in the following sources: Karma 'phrin las 1993, 66-124, 200-209; Ston pa shakya thub pa 2008, 37-38, 149-92, 256-63; Adarshah 2020.

24 Ston pa shakya thub pa $2008,149$.

25 Sde dge bka' 'gyur, 27-1-356b; cited in Adarshah 2020.

26 Karma 'phrin las 1993; Ston pa shakya thub pa 2008. As assessed from A Catalogue of the Comparative Kangyur (bKa' 'gyur dpe bsdur ma; Hackett 2013), a critical edition compiling and comparing the eight Kangyur editions (Tauscher 2015, 109). 
consume [the body], sustain [its] health, and produce disease. All the activities of wellness and illness amass [like] a vast ocean. ${ }^{27}$

The passage then describes sinbu functions in various body regions, including hair, skin, eyes, ears, mouth, teeth, gut and other organs, muscle tissue, and even blood. Sinbu, and its dynamic interactions of types, functions, and physiologies that provide diverse beneficial, neutral, and antagonistic relationships with the body and mind-from early development through the life course, form an analogous concept to the microbiome in Euroamerican biomedicine.

In the Euroamerican tradition, the microbiome was initially defined in 1988 by plant pathologist John Whipps and colleagues working on rhizosphere ecology and soil microorganisms influencing root secretions and metabolite exchange. ${ }^{28}$ They defined the microbiome as "a characteristic microbial community occupying a reasonably well defined [sic] habitat which has distinct physio-chemical properties," referring not only to the microorganisms but "their theatres of activity."29 Nobel Prize-winning molecular biologist Joshua Lederberg later updated this definition to specify its inclusion of commensal, symbiotic, and pathogenic microorganisms within body spaces and other environments. ${ }^{30}$ And environmental biologist Gabriele Berg and colleagues provided the most recent definitive reframing as the "diverse hierarchies of interactions of microbes with one another and with the host biotic and abiotic environments." ${ }^{31}$ This definition integrates what researchers now recognize of the microbiome in its inclusion of all microbial life-bacteria, eukarya, arachaea, and viruses ${ }^{32}$ - and their nutrients, products, and functions. The microbiome is critical for our most central organ systems-skin, ears, eyes, nostrils, oral cavity, digestive tube, and reproductive regions, ${ }^{33}$ as well as structures and biochemical activities for normal angiogenesis, immune and neural development, detoxification, energy metabolism, and cognition. ${ }^{34}$ They are intimate partners, agents, and subjects of coevolutionary trajectories,

27 Ston pa shakya thub pa $2008,15^{2-53}$.

28 Walker et al. 2003.

29 Whipps, Lewis, and Cooke 1988, 176.

$30 \quad$ Lederberg $2020,8$.

$31 \quad$ Berg et al. 2020, 103 .

32 See, for instance, Vemuri et al. 2020 and in the context of inflammatory bowel disease, Matijašić et al. 2020.

33 Dominguez-Bello and Blaser 2011; Heintz-Buschart and Wilmes 2018.

34 Bäckhed et al. 2005; Mayer 2011; Hooper, Littman, and Macpherson 2012; Kamada et al. 2013; LeBlanc et al. 2013; Claus, Guillou, and Ellero-Simatos 2016; Gilbert et al. 2016; Sarkar et al. 2018; Amedei and Morbidelli 2019. 
ecosystem networks, and interdependent symbioses, ${ }^{35}$ and integrally implicated in gut-brain/mind-body/intra-inter relational pathways of development, life-course health, and even death and dying processes. ${ }^{36}$ Their chemical products, nutrients, signaling molecules, and other cytosolic components influence each other and their host. ${ }^{37}$ This definition of the microbiome, including its innumerable biotic and abiotic elements, closely aligns with the concept of sinbu and its diversified interactions, functions, and layers of engagement with mind-body pathways. ${ }^{38}$ As such, the complex types and networks of sinbu and their body-mind-environment interactions form what we propose can be thought of as a "Sowa Rigpa microbiome."

The late contemporary Tibetan physician-scholar Jampa Trinlé described the functions of sinbu:

There are 84,0oo sinbu that reside as coemergent in the body and, in a balanced state, provide strength and radiance to the body, enhancing longevity as well as protecting vitality and sensory organs. They facilitate the capacity for dexterity. In imbalance, they produce diseases of various types. $^{39}$

In defining sinbu, he describes it as

a term for the coemergently existent and minutely small internal and external organisms that cause sin disease when disturbed. In terms of classification by type, there are those that collect in heaps, rlung-related that are elongated, and tripa-related that are body hair- and needle point-like. Classified by location, there are those of lice and its eggs [that reside in specific locations], as well as those that affect the eyes, teeth, skin, rectum, and genitalia, which are traditionally classified. ${ }^{40}$

In the fiftieth chapter of the Oral Instructions Treatise of the Four Medical Treatises, sinbu illnesses are any condition of the blood, gut, skin, lungs and

35 McFall-Ngai et al. 2013.

36 Sommer and Bäckhed 2013; Can et al. 2014; Mayer, Tillisch, and Gupta 2015.

37 See, for instance, Wikoff et al. 2009 on mass spectrometry analysis of blood metabolites for systemic effects of gut microflora. John Rawls, personal communication, February 13, 2021.

38 For clarification, the term sinbu refers to the microorganisms themselves and not microorganism-derived chemicals. However, sinbu types are classified not only by their morphology but their related physiological activities, which implicate nutrients/products with which they are associated and produce as well.

40 Ibid., 956. 
other orifices, organs, tissues, and fluids in which sinbu infection occurred. ${ }^{41}$ Infections that spread from one individual to another are known as rim diseases (rims nad).

Host-microbe relations in the Euroamerican paradigm span those that are pathogenic, such as in the case of SARS-CoV-2, to mutualistic where one organism benefits without harm to the other, and symbiotic or commensal where both host and microbe receive mutual benefit. ${ }^{42}$ In a similar way, sinbu also engage in beneficial, neutral, and harmful relations with the bodytransferring such effects to the bodies of others through communicable means depending on local, systemic, and environmental imbalances in which it partakes and is implicated.

\section{Understanding Infection (rims) and Virulence (gnyan)}

Communicable or infectious diseases known as rim diseases (rims nad) are conditions that spread to others upon exposure, contact, or proximal transmission. They primarily encompass fevers, dysenteries, and other hot diseases for which the Four Medical Treatises dedicates four chapters in the Oral Instructions Treatise, and virulent forms, called nyenrim, which comprise eighteen additional chapters. Nyen illnesses (gnyan nad) generally are described as an illness class which imparts particularly intense suffering coming from sinbu (microorganisms), toxin-containing entities, and barbata, a term for a considerably virulent class of pathogens, from the external environment, as well as those which reside in the body as primarily blood microorganisms, with round, red, and appendage-less appearances. The term itself confers the severity of the class of illnesses. ${ }^{43}$

One of the noteworthy additions that seventeenth-century Tibetan medical scholar and polymath Desi Sanggyé Gyatso (Sde srid sangs rgyas rgya mtsho, 1653-1705) makes throughout his commentary on the Four Medical Treatises known as the Oral Instructions Supplement (Man ngag lhan thabs), is the addition of nyen to various illnesses to indicate their degree of severity and virulent etiological origins. For example, he classifies infection-driven head conditions that impact the brain (gnyan nad mgor babs klad gzer); infection-derived neuromuscular pains (gnyan nad gzer thung ngam stod gzer); infection-associated abdominal cramps (gnyan rims pho glang); infection-generated méwel (gnyan rims me $d b a l$ ), which are burn-like infections and ulcers; infection-originated lymph disorders (gnyan rims rmen bu); and several others. ${ }^{44}$ Desi Sanggyé

\footnotetext{
41 G.yu thog yon tan mgon po 20o6: 369-72.

42 Bäckhed et al. 2005.

43 Byams pa'phrin las 2006, 281.

44 Sangs rgyas rgya mtsho 2005 , xi-xii.
} 
Gyatso introduces gryan 'bras, or malignant forms of tumors arising from virulent causes, in both his chapter on treating nyen illnesses as well as in that on abnormal growths, or 'bras nad. ${ }^{45}$

In contemporary use among Tibetan physicians in Xining, Lhasa, and Dharamsala, nyen conditions comprise a category of contagious disease that often delineates those illness classes that are most infectious and transmittable with the potential to instigate epidemics. For example, bubonic, septicemic, and pneumonic plagues, Ebola, and sars have all been classified as nyenrim illnesses, as particularly contagious forms of nyen. In contemporary practice, nyen conditions are often identified as those derived from a virus, bacteria, amoeba, or other pathogenic vector. Nyen provides the term rim with the connotation of virulence, denoting the severity or harm it can inflict. A few of these nyenrim conditions occur only very rarely and, because they have no specific treatment, are said to have the capacity to ruthlessly eliminate a quarter of living beings on earth. ${ }^{46}$ Tibetan physicians in March and April 2020 early in the pandemic reflected on the possibility that CoviD-19 could develop to qualify as one of these rare forms.

\section{Nyépa as Body Systems of Balance and Imbalance}

In addition to the framework of the degenerate age and the concepts of sinbu, rim, and nyen, the final theoretical foundation important to understanding virulent infectious disease from the Tibetan medical perspective, and specifically that of COVID-19, is that of its psychophysiological systems called nyépa (nyes pa). ${ }^{47}$ The concept of nyépa links body tissues, fluids, and organs in structure-function-activity relationships to create three distinct yet interdependent gross body systems called rlung (rlung), ${ }^{48}$ tripa (mkhris pa), and béken

45 Ibid., 195, 366. For further analysis, see Tidwell 2019.

46 Sangs rgyas rgya mtsho 2005,195 .

47 Due to their multivalent and applied use, the three nyépa have been translated and interpreted in many different ways (Gyatso 2005-2006; Gerke 2010). See Gerke 2010 for a discussion on the challenges of translating Tibetan medical terms into English; and Czaja 2015 for illustrative examples. To retain a more literate translation, since the term nyépa refers to disease-causing activity (lit., "faults" for disease) yet has wider functional physiological roles, Yonten Gyatso (2005-2006) aptly translates them as "defaults." We follow Gyatso's lead in our translation. Although the term duwa ('du ba) technically refers to the functional form, nyépa is often interchanged for duwa in the Four Medical Treatises from which context determines meaning.

48 Pronounced lōong. Although the standard phonetic conversion for rlung is lung (Germano and Tournadre 2010), we will retain the Wylie spelling rlung to distinguish the term and disambiguate it from the organ. 
(bad kan). These systems enact the functions of motility and psychophysiological signaling; ${ }^{49}$ metabolic heat, blood production, and thermoregulation; and fluid-nutrient cycling, filtration, joint lubrication, and solidity/cohesion, respectively. Each gross system has five subtypes responsible for specific functions, comprising fifteen distinct physiological systems. The etymology of the Tibetan term nyépa refers to the systems' activity as the primary instigators of disease and imbalance in the body, like a potential weakness that could befall the Achilles heel and result in systemic debilitation. Yet in balancethat is, without specific causal factors and inciting conditions to instigate their imbalance - the nyépa enact the life-sustaining activities of body and mind.

\section{Entering the Body: Causal Factors, Inciting Conditions, and Modes of Infection}

The Four Medical Treatises and its commentaries describe two dimensions to the causal factors and inciting conditions for epidemic infectious disease (nad yams). The first is that epidemics result from poor behaviors contrary to Buddhist philosophical views; and second, that epidemic infections are precipitated by dietary and lifestyle behaviors contrary to seasonal, temporal, and climatic conditions.

\section{Causal Factors and Inciting Conditions}

Regarding the first causal factor in which transgressive behaviors provide conditions for the manifestation of an epidemic, the Four Medical Treatises states:

The causes and conditions that originated the disease called rim occurred at the beginning of the final cycle of the ten five-hundred-year cycles, whereby the desires of humankind led to much transgressive behavior; rampant murders of vajra siblings spread among ngakpa [tantric practitioner] communities; monastics engaged in bitter quarrels within their sangha; extremists committed harm to others; and groups took vows to war and slaughter many. At that time, the mamos [who are wrathful and

49 Since rlung is defined primarily as any motility ( $g . y o b a)$ in the body (G.yu thog yon tan mgon po 1999, 6o), its functions most closely align with the neuroendocrine system (ibid., 58-59), providing integral communication between mind and body and enacting their functions. As such, "signaling" is a primary function of rlung since the mind rides upon rlung like a horse on a rider. For further discussion, see Tidwell 2019. 
deceptive] dākinis were enraged and the breath of disease manifested immense variegated clouds and gave rise to epidemic infectious disease, dysenteric conditions, pulmonary infections, contagious ulcerative illnesses, and pustule-forming diseases. ${ }^{50}$

The five-hundred-year cycles to which this passage refers are specific periods delineated by characteristics related to the doctrine of the Buddha. In the final cycle, a degenerate era is predicted, characterized by greed, disease, toxins, mass fires, degradation of ethics, and proliferation of superficiality. The five specific degenerations expected during this time are: (1) the degeneration of life spans, where all organisms' lives shorten; (2) the degeneration of time, in which wars, famines, toxins, cataclysms, and disease spread; and the deterioration of qualities of the animate and inanimate, such that even grain becomes less savory, nutritious, and mature; (3) the degeneration of mind, such that afflictive emotions proliferate; (4) the degeneration of views, from which false beliefs spread and practitioner virtues decline; and (5) the degeneration of beings' experiential worlds, in which bodily constituents and sensory faculties deteriorate, making benefiting beings difficult. ${ }^{51}$ This current era is thought to be the degenerate age.

As the passage describes, mamos become enraged in this period and manifest widespread disease. Mamos are wrathful female deities and spirits that are associated with the various forces of the natural world, responding to and enacting retribution for behavioral misconduct and environmental harm. They react to negative activities by inflicting disease, obstacles, and environmental cataclysms on offenders. The passage continues that, during this time, "Ill-intended extremists create compounded chemicals and substances" and the mamos respond by waging retribution, "striking down with vicious epidemic disease." 52 The production of chemical substances by "extremists," or those without others' well-being in mind, is seen to contribute another condition in manifesting epidemics. Not only exacerbating environmental injury, perpetuating harm across life-forms, and disrupting ecological homeostasis, it is seen to inhibit resources to treat rim conditions, since food, water, medicine, and environments become toxic. Ekadzati (Skt. Ekajatīi), one of the protectresses of the Tibetan medical lineage also has an entourage of mamos that assist her in protection activities, including ecological. There are many kinds of

\footnotetext{
$5^{\circ} \quad$ G.yu thog yon tan mgon po 20o6, 278.

51 Dilgo Khyentse Rinpoche 1999, 5 o.

$5^{2}$ G.yu thog yon tan mgon po 2006, 278.
} 
mamos - mamos of wisdom, mamos with special karma, and worldly mamos, the latter of which is a type of preta, or hungry ghost. ${ }^{53}$ However, the mamos in the passage above are those of wisdom, acting in the service of the dharma and the protection of all sentient beings, while administering consequences on those who inflict harm and participate in unethical conduct. ${ }^{54}$

Thus, behaviors that are contrary to Buddhist philosophical views such as committing any of the ten nonvirtues, are also recognized as causal factors and inciting conditions of epidemics. Such behaviors include practitioners breaking vows to teachers; not maintaining samaya —Vajrayana commitments conferred in empowerment rituals; and instigating quarrels among one's spiritual community. Mental afflictions are also predicted to proliferate during this period, so behaviors motivated by greed, jealousy, lust, rage, and ignorance are expected to increase manifold, and likewise instigate the rise of virulent infectious disease. Harm toward other sentient beings is included among these behaviors, such as that inflicted by disrupting the natural environment-on global scales as well as local. It includes injurious or detrimental behaviors to all beings in the extended cosmic sociality. 55

The Oral Instructions Supplement further elaborates on this first causal factor:

The causes [ultimately] arise from the three [mental] poisons [and are specifically] the intensely afflictive environmental influences (gdon) the eight classes of beings and others [that inflict suffering of mental and environmental origin]. Also, ill-directed, unwholesome, and inappropriate behaviors have angered the hearts of our protectors and caused even deities to become demons. ${ }^{56}$

This passage highlights the specific role of the three mental poisonsattachment, aversion, and delusion-in inciting destructive behaviors and mindsets that lead to epidemic-producing causal factors and inciting conditions. Specific in this causal trajectory is how these behaviors and mindsets inflict harm and disruption to the environment and instigate its animated retribution. The negative influences to which this passage refers stem from what are called dön (gdon). Dön are nonhuman external influences, technically

\footnotetext{
53 A subclass of sentient beings. See Patrul Rinpoche 1998, 75 .

54 Specifically, the ten nonvirtues (Patrul Rinpoche 1998, 75; Nāgārjuna 2007, 35).

$55 \quad$ Fjeld and Lindskog 2017.

$5^{6}$ Sangs rgyas rgya mtsho $2005,134-35$.
} 
eight classes of beings and other associations, that create afflictions via mental and environmental associations, such as skin diseases as retaliation for polluting waters, forests, and mountain passes where dön reside. ${ }^{57}$

The extended socialities that humans forge with these seen and unseen beings in the Tibetan cultural landscape create a rich cultural, environmental, and cosmological landscape of spirits that protect natural resources, guide climatic occurrences, and steward the balance of relationships between animate and inanimate as well as the innumerable life-forms intimately and interdependently connected for survival and well-being on this planet. ${ }^{58}$ Dön are seen as responsible for inflicting disease that is environmentally originated, including but not exclusively stemming from zoonotic sources, viral infections, pathogenic exposures, and topical and systemic inflammatory conditions.

In one sense, these conditions can be seen as the result of externally transgressive behaviors that disrupt the ecological and cosmological balance to give rise to pathogenic organisms such as viruses. However, these conditions also point to the importance of internal conditions in that mental-emotional transgressions upset the balance of the ryépa (and their respective functions) and create specific susceptibilities to disease, such as dampened immune systems, overactive inflammatory responses, and poorly functioning stress physiologies. ${ }^{59}$

Regarding the second causal factor for the rise of epidemic infectious disease - that of engaging in dietary and lifestyle conduct contrary to seasonal, temporal, and climatic conditions, the Four Medical Treatises states:

Other causes [of infectious disease] also comprise changes in the seasons that are in excess, deficiency, or adversity to the norm; exhaustion due to excess physical exertion; contagious transmission of illness; contact with toxins and poisons; extreme rage and fear; severe mental distress; and excess attachment and greed. It also includes consumption of unsuitable or contaminated foods that cause infectious disease (rims). ${ }^{60}$

During the annual cycle of seasons, various seasonal characteristics of humidity, temperature, pressure gradients, and ecological effects differentially influence the nyépa body systems, creating susceptibilities and vulnerabilities to

57 G.yu thog yon tan mgon po 2006: 442-43. For an analysis of gdon conditions and their relationship to chronic inflammatory conditions, see Tidwell, Nianggajia, and Fjeld, forthcoming.

$58 \quad$ Fjeld and Lindskog 2017.

59 Tidwell, Nianggajia, and Fjeld, forthcoming.

6o G.yu thog yon tan mgon po 20o6, 278. 
specific kinds of conditions. Often proclivities for specific illnesses and imbalances in one season are resolved by the next season through the normal ebb and flow of accommodations the body creates in the nyépa systems accounting for and adapting to normal seasonal fluctuations. For rim conditions, however, when a season manifests characteristics unlike its norm-in excess, deficiency, or contrary qualities — rim conditions are more likely to manifest in the environment, and individual bodies tend to be more susceptible due to a lack of adaptive familiarity with how to compensate for abnormal conditions. For example, an unusually hot or extraordinarily wet summer season can disrupt ecological cycles such that insects or other vectors become more plentiful with a given parasite, bacterium, or virus, and human populations may spend more time in environments exposed to such microorganisms than in a normal season. Likewise, population-level immune function may be dampened from increased exposure to temperature or climatic extremes. Amid global climate change, these abnormal and extraordinary seasonal characteristics, including erratic and unpredictable weather events, have become more widespread and common. Thus, from the perspective of these classic texts, we can expect more frequent and intense devastation caused by epidemics due to disturbances in the natural seasonal cycles and the related adaptation difficulties our bodies experience.

The other components that the above extract describes relates to pathogen exposure and conditions that weaken the physical body and its ability to fight infection. These include excess physical exertion that weakens the body, as well as extreme emotions such as rage, fear, and severe mental distress that may disrupt the normal and appropriate activation of immune-inflammatory response. Exposure to contagion through contact with contaminated food, persons, and surfaces and areas also provide causal factors for the widespread transmission of infection, and excess attachment and greed can lead to poor behavior and increase exposure. Subjection to toxins or poisons further weakens organ systems and viral defense mechanisms, leading to greater exposure as well. From this selection, the role of comorbid, congenital, and inherited characteristics that further inhibit the body's defense against viruses is also clear. Embodied vulnerabilities can occur predevelopment to across the life course. For example, maternal dietary and behavioral exposures on the developing fetus initiate persistent long-term health trajectories, just as parental hereditary material lays potential blueprints. The fifth chapter of the Explanatory Tantra likens this process to sinbu exposures with harmful or noxious capacity (dug can srin bu) that gradually inflict harm over time. It states: "Just as sinbu with noxious qualities produce noxious effects, [initial imbalances of the nyépa] are produced in the womb as with the first constituents of 
development, the seminal fluid and ovum."61 Later in childhood and throughout the lifetime, various dietary, behavioral, psychological, environmental, and season conditions can lead to subsequent nyépa imbalances, ${ }^{62}$ and likewise the adventitious conditions for noxious effects from virulent sinbu to occur. ${ }^{63}$

\section{Modes of Infection}

The way disease actually penetrates and manifests in the body, the Four Medical Treatises describes as modes of infection ('jug tshul). Sinbu as pathogens use a combination of maneuvering body portals and adjusting to the body's susceptibility and reaction to those pathogens in situ. ${ }^{64}$ This latter component is the environment of the host, namely the likelihood that a sinbu will create imbalance and dysfunction to the nyépa body systems, organs, fluids, and so forth, and the mode in which various bodily constituents are implicated in those processes. Each individual differs in its response to a given sinbu, due to differing strengths and functionalities of their nyépa systems. This is similar to the Euroamerican perspective even for SARS-CoV-2, where immune-compromised individuals are more infection susceptible, ${ }^{65}$ and growing understandings of the "SARS-CoV-2/Microbiome Nexus" 66 demonstrate that imbalances, disruptions, and profiles of the human microbiome in the lung and gut might be involved in or affected by SARS-CoV-2 infection and the severity of disease presentation. ${ }^{67}$

From the Tibetan medical perspective, nyépa system disruption leading to infection susceptibility can occur when normal physiological pathways incur weakness or damage and allow for pathogenic intrusion to manifest disease. The twenty-third chapter on infectious disease of the Oral Instructions Treatise from the Four Medical Treatises describes:

The causes and conditions [of infectious disease] provoke the metabolic fire of tripa, incite heat to pervade the body, activate perspiration, and sequentially provoke béken, tripa, and rlung. By sequentially entering the body's six modes of entry or by infecting through contaminated contact,

\footnotetext{
$61 \quad$ G.yu thog yon tan mgon po 1999, 57.

62 Ibid., 70-77.

63 G.yu thog yon tan mgon po 2006, 370.

64 Key to note here is that nonharmful sinbu - that is, those not causing disease but supporting physiological function-can also enter the body through these modes of entry.

65 CDCP 2021.

66 MCCCC 2020 .

67 Gu et al. 2020; van der Lelie and Taghavi 2020; Zuo et al. 2020. The authors thank John Rawls for pointing us to this literature.
} 
it epidemically transmits. For this reason, it is called "rims" — named for its sequential transmission. ${ }^{6}$

Here, the stanzas emphasize the role of initial conditions-the synergy of causal factors and inciting conditions to enact a set of reactions in the body, namely systemic fever from stoking tripa's thermoregulatory system and increasing its metabolic activity. This also stimulates perspiration, activates lymph, blood, and interstitial fluid functions, and generates conditional responses in other nyépa organs, fluids, and pathways. There are six modes of entry - physiological layers sequentially penetrated by disease that cause increasing severity of symptoms and access to vulnerable organs and systems. These modes of graduated entry comprise: (1) infiltrating superficial layers, (2) penetrating muscle tissue, (3) circulating through vessels, (4) invading vital organs, (5) descending into vessel organs, and (6) suffusing into bone tissue. Such entry trajectories can be described in terms of tissue type as well. The rim chapter clarifies that "superficial layers" (lpags) include pores (ba spur), epithelial or cortical layers (skyi), and skin epidermis (lpags); muscle tissue includes skin dermal layers as well connective and muscle tissue types of flesh. Vessels include blood, neural and lymphatic, delineated as dark (rtsa nag), light ( $r$ tsa dkar), and glandular (rmen bu'i rtsa) vasculature, respectively. The vital organs ${ }^{69}$ are impacted before vessel organs, ${ }^{70}$ and bone and cartilaginous tissue last. This sequential penetration of exposure increases depth of impact and level of severity - further elucidating the term rim (rims) in Tibetan, which literally connotes a sequence of events or related activities.

The rim section of seventeenth-century CE Blue Beryl (Vaidūrya sngon po) commentary by Desi Sanggyé Gyatso, describes the modes of entry further:

[Out of the major] entry orifices for disease-eyes, ears, nose, mouth, urethra, and anus - it is said that the universal and most predominant is merely the entrance through the nose. Whether it is the actual diseased contaminant or an area in which the disease is present, aerosolized particles, air currents, and so forth can cause infection by contact with the contaminant and then sequentially transmit contagion further. ${ }^{71}$

68 G.yu thog yon tan mgon po 2006, 279.

69 Heart, lungs, liver, spleen, kidneys.

70 Stomach/pancreas, small intestine, colon, gallbladder, urinary bladder, reproductive vesicles.

71 Sangs rgyas rgya mtsho 2005,195 . 
Whereas the previous section referred to the sequential penetration of layers by disease, this section refers to orifices of entry. Although Desi Sanggyé Gyatso notes that all major body orifices provide potential entry, he identifies the nose as the primary portal for infection. He explains the rationale that virulent infectious disease tends to transmit, not only through physical contact on surfaces and persons, but through aerosolized exposures such as coughs, sneezes, shared air spaces, and close proximity. Later he adds that even quality, density, and directionality of air currents affect transmission.

\section{Nyenrim: Virulence Characteristics, Pathogenic Nature, and Subtypes}

The complexity of nyenrim conditions, including numerous causal factors contributing to their manifestation, the pathophysiological diversity for those infected, and numerous subtypes differentiated by constitutional characteristics, affected region, and symptom progression severity, make them complicated conditions to diagnose, treat, and prevent. The Four Medical Treatises describe six characteristics that make a rim condition, or infection, a virulent form.

First, the condition will not only derive from a tenacious sinbu, or nyen, but the host will exhibit highly pronounced heat and rlung imbalances. One can think of this as an elevated inflammatory response or pronounced stress reaction that significantly impacts the neuroendocrine system. Second, the condition is usually difficult to diagnose by traditional means of observation, palpation, and patient inquiry due to its semblance to many other infectious diseases. Third, if not treated expediently, it can endanger life. Fourth, due to rapid transmission rates vis-à-vis bodily fluids and waste products, increasing exposure within communities of close proximity, it has the capacity to eliminate a quarter of living beings on earth through direct and accessory suffering caused by the illness. We see this potential in the case of Covid-19 where the breakdown of human systems also disrupts and affects many ecologies including domestic animals and wild species in related contexts causing many deaths, human and nonhuman. Fifth, its threat to life also stems from its ability to evade response to most treatments. Although it presents similarly to other contagious conditions, most applied treatments produce ineffective results. Finally, virulent forms of infectious disease are seen to be the result of past actions in which present experience is bearing fruit.

Thus, to address present harm caused by the disease, actions need to remedy further contributing conditions that continue to reap results of the 
manifesting epidemic. In the case of CoviD-19, some factors that need to be addressed include environmental destruction, such as those leading to viral populations and mutations in bat, pangolin, or other wet market species; the behavior of consuming those species; and the harvesting of viruses for manipulation studies with potential for error and accidental release. Widespread structural conditions and social activities, including extensive global travel, poor conditions in city centers, and adverse contexts for many disadvantaged communities with inordinate potential exposure and inaccessibility to definitive care, would also need attention for the pandemic to dissipate, global populations and ecosystems to recover, and resilience to develop against future vulnerability.

Virulent pathogens, or nyen sin (gnyan srin), have a unique place in the Tibetan medical nosological world. They are known by the term tretreho, or barbata, and described as having specific shapes such as that of a lizard head, gaping snake mouth, comet tail, or centipede, like the Ebola virus or cholera and diphtheria bacteriums; and in blood, rounded, tail-less forms, like that of poliovirus and the SARS, MERS, and SARS-CoV-2 coronaviruses. Nyensin are known to be imperceptible to the naked eye and many are easily mobilized by air currents. Although all nyenrim can enter body orifices, the Four Medical Treatises describes that virulent pathogenic types have increased access to and mobility through skin pores, nostrils, and other body orifices.

Nyenrim conditions also manifest as different types depending on affected body region, viral pathogen, and condition severity. Table 1 lists a selection of nyenrim types named for body region affected.

As seen in the selection of nyenrim disease types related to affected regions in Table 1, some nyenrim are not considered epidemic-level conditions, while others have demonstrated historical evidence for epidemic effect, such as bubonic plague, smallpox, measles, malaria, influenza, typhus, diphtheria, dysentery, yellow fever, and poliomyelitis. Although the table lists some nyenrim that tend to primarily affect specific regions of the body, most nyenrim present more systemically, affecting multiple body systems. These include yellow fever, cholera, malaria, and Ebola. COVID-19 tends to manifest primarily as upper respiratory inflammation, such as in rimcham (rims cham) and zertö (gzer stod) forms, but has persistent systemic effects due to significant tripa-rlung influence causing high degrees of sustained inflammation affecting heart, kidneys, brain, and vasculature, in addition to lung and upper respiratory pathways. ${ }^{72}$

72 For further descriptions of physiological effects of rlung-tripa imbalances, see Tidwell 2019, 2020a. 
TABLE 1 Selection of virulent infections (Nyenrim): classed by dominant affected region and related disease type

Affected region

\section{Condition name}

Brain (klad pa)

Viral encephalitis (klad gzer)

Throat (gre ba)

Pharyngitis, laryngitis ( $g a g$ pa), diphtheria

Upper body (ro stod)

Upper respiratory inflammation (gzer thung)

Stomach (pho ba)

Viral gastroenteritis (gnyan glang)

Small intestine (rgyu ma) Cholera, dysentery, and severe diarrheal conditions (rgyu gzer)

Skin (lpags pa)

Méwel ulcerative skin conditions (me dpal), smallpox ('brum rims), measles (beg ge'am sib bi), and other pustule-forming conditions ('brum bu)

Bone joints (rus tshigs) Epidemic viral arthritis (grum rims), lymphadenitis (rmen bu), and lymph system bubonic plague (gnyan rims rmen bu; bal tshad)

(rmen bu)

Calf muscle (nywa gnad) Viral myositis (nywa log)

Muscle tissue (sha) Ulcerated sores $(\operatorname{lhog} p a)$

Muscle, bone, vessels, $\quad$ Viral-driven cancer and neoplasms (gnyan 'bras)

interstices (sha rus rtsa

bem'drul)

Medulla oblongata Viral meningitis/encephalitis ('dzum bu ltag dgye)

(rgyungs pa)

Gallbladder and liver

Viral biliary tract and duct infections, hepatitis, trétrého, etc.

(snod mkhris) (rtsar rgyug / rims sbyon tre tre ho / rgya nag mig ser / nag po gsum 'grim)

Central nervous system, Poliomyelitis, internal ulcerative conditions (nang lhog) vital and vessel organs (srog rtsa don snod)

\section{Preventative Measures and Diagnostic Signs}

Prevention of nyenrim infection includes behaviors focused on external protection as well as internal defense mechanisms. The Oral Instructions Supplement describes: "Mantras in diagrams are advised for external protection; diet and behavioral conduct provide important internal protection."73 Mantras in dia-

73 Sangs rgyas rgya mtsho 2005,195 . 
grams, known as yantra in Sanskrit, refer to talismans and amulets connected to rituals conferring them with protective qualities through association with specific deities and protectors, such as Vajra Armor. External protection refers to ritual and consecrated substances used by physicians, nurses, and caretakers specifically, and the public generally, to ward off infection; as well as behavioral measures used for exposure protection.

Specific measures used by physicians and healthcare workers include adorning one's neck with the Nine-Compound Black Pill or Vajra Armor Protection Pill as protection substances (rdzas srung); ${ }^{74}$ wearing the Epidemic Protector Amulet as a yantra amulet form of mantra protection (sngags srung); and various encryptions and reminders of dhāran̄i (gzungs srung; lit., "that which holds") as protection methods by keeping the dharma and its teachings in mind to affect body, speech, and mind behaviors important in disease prevention. The general public can also use these methods but individuals vary in training of their use, as well as in ritual substance access itself. Since healthcare workers incur greatest exposure in providing care, they receive priority access. During the COVID-19 pandemic, however, lay Tibetans in Tibet, India, Nepal, and worldwide used the Nine-Compound Black Pill extensively both in and outside the home.

More general protection measures used universally are the recommended dietary and behavioral measures for cultivating resistance to infection. In the section on inciting conditions that give rise to virulent infectious disease in the nyenrim chapter of the Four Medical Treatises, there are three distal methods described: (1) vigilantly refrain from improper behavior of body, speech, and mind; (2) observe causal relations to guide behavioral choices; and (3) engage in contemplative techniques such as resting the mind in the natural state. As described above, proper behaviors of body, speech, and mind include refraining from the ten nonvirtues and upholding virtuous conduct; reducing afflictive emotions and developing wholesome mental states focused on cultivating compassion for self and others as well as establishing insight into the nature of reality, impermanence, and no self. Maintaining attention to causal relations motivates an observational basis for implementing methods that protect one from exposure and infection and keep one safe. The reference to meditational practices describes approaches such as in Mahāmudrā and Dzogchen of discovering and abiding in the ultimate ground of existence without attachments, aversions, or delusions, and imbued with qualities of luminous clarity

74 See Gerke 2020 and Tidwell $2020 \mathrm{~b}$ on the use of these protection substances during the covid-19 pandemic. 
of mind and vast compassion. ${ }^{75}$ Such states are understood to provide not only heightened states of awareness but also a more resilient body and a mind less susceptible to affliction. Contemporary neuroscience research on contemplative practices demonstrates heightened immune responses among long-term meditators of related practices. ${ }^{76}$

\section{External Proximal Approaches to Prevention}

The proximal methods for infection resistance are described in the Four Medical Treatises as the following:

Protect the nostrils from aerosolized particulates, as well as body fluid and pores from contact. Also, critically protect [body entryways] from both vapors and light radiation, such as from the sun. Thus, protect the victorious pathways from all. ${ }^{77}$

This passage describes that aerosolized particles can be infected and one must be careful to protect orifices from particle entry, for example by covering mouth and nose. The reference to vapors and sun rays conveys the role of air currents, breath, and imperceptible vapors as potential vehicles for microbial transport, including viruses. Light radiation relates to a subset of virulent infections in which sunlight radiation may play a significant role in disease progression. For example, in Herpes simplex virus 1, sunlight is a potent stimulus for reactivation or recurrent flare-ups ${ }^{78}$ and extended exposure in direct sunlight may also induce immunosuppression.

Another proximal behavioral approach in creating resistance is strengthening the body through dietary sustenance. The Four Medical Treatises continues:

Likewise, it is particularly important to protect from infection when hunger and depression manifest. The protection of a satisfied full stomach will embolden you with courage when the time comes. ${ }^{79}$

On the one hand, maintaining a strong digestive fire with a nourishing diet facilitates the proper development and maintenance of bodily constituents and nyépa systems, producing a robust, resilient body more resistant to

75 Dakpo Tashi Namgyal 2004.

76 Kaliman et al. 2014; Rosenkranz et al. 2016.

77 G.yu thog yon tan mgon po 2006, 279.

78 Ichihashi, Nagai, and Matsunaga 2004.

79 G.yu thog yon tan mgon po 2006, 279. 
infection. If infected, a strong physical foundation provides greater endurance in withstanding the physical and mental hardships of virulent infection. This passage also notes the role of depression, or a depressed affect (sems shum), in similarly weakening the body's ability to fight off infection.

\section{Internal Measures for Prevention}

In terms of internal protections against infection, the texts describe both diet and medicinal aspects. The rim diseases chapter in the Four Medical Treatises instructs: "If you take daily medicine formulations of a few ingredients, it will protect you well." 80 This passage refers to a class of medicines in Sowa Rigpa called tang (thang), or decoctions, in which formulas of a few ingredients confer fast-action delivery of medicinal benefits. They target fevers and hot-natured illnesses by slightly intensifying heat, breaking fever, and consequently neutralizing the virus. ${ }^{81}$ Taking daily decoctions prevents infection development, although other decoctions are administered as treatment.

The Oral Instructions Supplement also describes: "The superior Mangjor pill is auspicious." ${ }^{82}$ Mangjor, or the Multi-Compound Pill, is a precious pill made of many herbal, mineral, and geological substances. It is known for its capacity to release toxins from the body and expel pathogens. ${ }^{83}$ The Four Medical Treatises adds several further recommendations: "For all rim conditions, take up fasting and hot water." 84 Though a strong diet is advised preinfection, postinfection benefits from a practice of fasting with conscious consumption of boiled water cooled to a palatable tea temperature. This reduces tripa heat "emboldened," or aggravated, by infection. Yet the digestive fire must sustain sufficient heat to clear infection. The Four Medical Treatises continues:

Take düdtsi and mendrup pills and integrate diets of balanced potency and nutritional content. Conscientiously attending to methods caring for mind and nourishing rlung is critical. ${ }^{85}$

Düdtsi (bdud rtsi) and mendrup (sman sgrub) are substances used for protection with blessings consecrated through ritual ceremonies understood to give the recipient greater protection from disease, infection, and harm. ${ }^{86}$ The

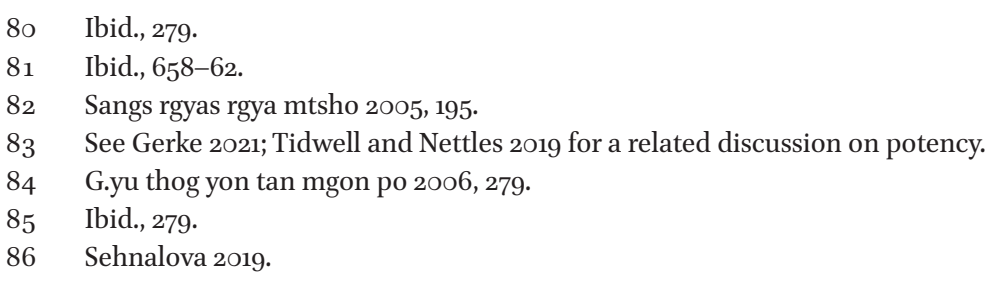


indication for diets of balanced potency and nutritional content refers to food and drink that are not too cooling nor overheating, not too dense in nutritional content nor unconcentrated, but balanced in both characteristics and qualities. Such an approach allows proper heat to be maintained with the fever without overaggravating nor overdiminishing the digestive fire. The final indication refers to foods, behaviors, and activities that nourish rlung. One can think of this as caring for the neuroendocrine system and protecting from behaviors that incite inflammation, depress immunity, and overactivate bodily stress responses. Practices nourishing rlung include contact with emotionally close relations, protecting from overstimulating sensory input, and keeping the body appropriately warmed, not exposing it to physical extremes. ${ }^{87}$

\section{Diagnostic Signs}

Though the diagnostic signs of virulent infectious disease (nyenrim) resemble those of many communicable diseases (rim), they exhibit particular symptom presentation severity. The Oral Instructions Supplement describes:

The first general symptom occurs a few days before [the full manifestation] presenting as greater irritability and anger. When the urge to rage or cry arises, loose bowels and vomiting occurs; and any preexisting illnesses and conditions worsen and aggravate. The [full] general symptoms include coughing, sneezing, sore throat and hoarseness, raw nose and mouth, burning up with fever, obstructed respiratory pathways, and runny nose. ${ }^{88}$

The passage illustrates the integral connection between cognitive-affective effects and those of the body in Sowa Rigpa etiological paradigms. Initial indications of infection first manifest as changes in the mental-emotional patterns of the individual increasing in frequency of instances of irritability and rage. The passage then recognizes a change in the gut processes by presenting as diarrhea or experiences of nausea and vomiting, and then a worsening of preexisting conditions, such as joint conditions, liver sensitivities, blood sugar regulation, and blood pressure spikes. Such initial signs indicate the first indications of infection when the body is demonstrating a weakening in both digestive equilibrium and its ability to address underlying health issues since a new aggravator-the virulent infection-is occupying its defense mechanisms.

87 G.yu thog yon tan mgon po 1999, 27-29, 187 .

88 Sangs rgyas rgya mtsho 2005, 195 . 
Full symptoms present subsequently. These include classic signs of upper respiratory infection but also point to underlying processes of inflammation.

For the eighteen types of virulent infectious diseases (nyenrim), there are differential diagnostics of signs and symptoms for each type and subclass. Since COVID-19 presents most saliently as rimcham or zertö, upper respiratory infections with restrained breathing, yet crosses over many subtypes, specific symptoms will not be presented here so as to minimize complexity.

\section{v. Treatment Approaches}

\section{Dietary-Behavioral Interventions}

Treatment approaches to virulent conditions can be divided into dietarybehavioral interventions and medicinal-ritual treatments. Regarding dietary interventions, the Oral Instructions Supplement describes: "Like pernicious poison, abandon diets rich in whites, reds, sweets, and sours." ${ }^{89}$ Diets "rich in whites" refers to dairy products of milk, yogurt, and butter. Such intake will increase mucilaginous development and further aggravate the upper respiratory tract. Diets "rich in reds" refers to red meat. Avoiding red meat during treatment is advised to minimize conditions in which the pathogen might thrive. Sweet-tasting foods are also seen to contribute to viral proliferation and sour-tasting food to excess heat production counterproductive to developing the fever in a controlled manner toward therapeutic break.

Regarding behavioral interventions, the Oral Instructions Supplement describes:

In a remote, secluded, dark location where one can remain undistracted, lay out a clean mat of goat fur and recline on a cushion. Avoid vow violators, widows [or similar in mourning], haunts, and visitors. Physicians and nurses should wear wild boar tusks [around the neck]. Avoid carrying objects and many of one's belongings [there] and [engaging in] instruments that make sound. Exert yourself in accumulating merit, conducting ransoming rituals and ceremonial offerings. It is said that those activities will completely paralyze virulent conditions. ${ }^{90}$

The behavioral recommendations illustrate the importance of taking rest and maintaining ease in a secluded environment. Such indications keep the

\footnotetext{
$89 \quad$ Ibid., 195 .

9o Ibid., 195 .
} 
patient from further exposure, but also protect them from unproductive emotions potentially stimulated by visitor interactions. The darkened environment also reduces rlung stimulation sensitive to intense light that can strain the senses and mind (and hence, dampen body strength and immune response). The recommendation for physicians and nurses to wear wild boar tusks is a reference to practices related to protectors, further buffering exposures. Avoiding carrying objects and belongings refers to the patient's need to abstain from excess exertion, and the potential for playing instruments that may aggravate rlung due to excess sensory stimulation as well as the superfluous use of sensory faculties and exertion.

The guidance to focus one's time on contemplative practice and ritual emphasizes the importance of engaging in dharma activities aimed at cultivating beneficial mental states and activities important as therapeutic conditions. It also increases potential for strong recovery, enhancing awareness of treatment and recovery means, and clarifying modes to protect from viral reactivation, further epidemic spread, and the consequent devastating effects socioecologically.

\section{Ritual, Practice, and Pharmacological Treatments}

In terms of different nyenrim treatment methods, the Four Medical Treatises and its commentaries enumerate a multitude of ritual, contemplative, and medicinal practices as potent. Table 2 enumerates various treatment methods and described types per method.

TABLE 2 Treatment types and related methods for virulent contagious disease

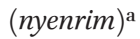

Treatment method

Types

$\begin{array}{lr}\text { Mantras (gzungs sngags) } & 20 \\ \text { Mantras in diagrams (srung 'khor = Skt. yantra) } & 5 \\ \text { Protection formulations (srung sbyor) } & 8 \\ \text { Decoction formulations (thang) } & 16 \\ \text { Pill formulations (ril sbyor) } & 16 \\ \text { Powder formulations (phye ma) } & 45 \\ \text { Cleansing formulations (sbyong sman) } & 10 \\ \text { External ointments (byug sman) } & 20\end{array}$

a Data based on G.yu thog yon tan mgon po 2006, 658-62; Sangs rgyas rgya mtsho 2005, 195 . 
Detailing the role, uses, and primary benefits of each treatment method and its types is beyond the scope of this work. However, put simply, the mantras, yantras, and protection formulations provide a range of external protections; whereas the decoctions, pills, and powders confer the medicinal activities of ripening the fever, bolstering organ activity, strengthening nyépa function, and debilitating the virus. The cleansing formulas may be administered to induce emesis, purgation, bowel evacuation, diuresis, and/or sweat induction to clear certain infections. And the external ointments ameliorate symptoms that have skin presentations. Pharmacological work on some of the formulas used in Tibetan medical therapeutics for CoviD-19, ${ }^{91}$ as well as on some of its individual herbs, ${ }^{92}$ has been conducted demonstrating modulation of the immune system and inflammatory response, protection of the vascular and neural structures, and antimicrobial, antiplasmodic, and antiviral activities. ${ }^{93}$

Since one of this article's authors has seen over three hundred Covid-19 patients among the Tibetan community in Canada, he has had the opportunity to examine a significant number of cases. ${ }^{94}$ Through this clinical experience, he has had the opportunity to engage in dialogue with colleagues in Tibet and India on the various institutional protocols developed for COVID-19 treatment over the pandemic duration. ${ }^{95}$ Through such experience and discussions, it is clear that CoviD-19 presents as a severe upper respiratory viral infection (gnyan nad stod gzer) compounded by tripa-rlung aggravation that has epidemic transmission capacity and tends to progress to affect vital organs. ${ }^{96}$ Some cases present as nyen-accompanied upper respiratory infections (rims chams) with more chronic persistent systemic inflammation. ${ }^{97}$

As is standard Tibetan medical practice, patients receive individualized treatment plans differentiated by patient constitution, stage of disease progression, comorbidities, and related mental and physical characteristics. Patients

91 Such as for the formulas Gabur 25, Drébu 3 Tang, and Pökar 10.

92 Such as for the herbs Tinospora cordifolia, Meconopsis simplicifolia (D. Don) Walpers, Aconitum laciniatum, Corydalis dubia, Corydalis crispa, Tribulus terrestris L, Ranuculus brotherusi Freyn, Ajania nubigena, Pleurospermum amabile.

93 Korwin-Piotrowska et al. 1992; Split et al. 1998; Wangchuk 2004; Exner et al. 20o6; Melzer et al. 2006; Vennos et al. 2013; Wangchuk et al. 2011, 2012, 2013, 2018; Zhao et al. 2018.

94 For comparison, total CoviD-19 cases in Tibetan regions of China had only reached eighty cases cumulatively by June 2020 (Tidwell $202 \mathrm{ob}$ ).

95 For the protocols developed among institutions in Tibet, see Tidwell 202ob. For the response by Tibetan medical institutions in India, see Gerke 2020.

96 At which point it is called zer tung (gzer thung; Tshul khrims 2011, 110-11, 188).

97 Tshul khrims 2011, 3. For further discussion on the nature of the disease from a Tibetan medical perspective and proposals for its classification with a new name within Tibetan medical nosology, see Rig 'dzin 2020, 56-63. See Tidwell 2019, 2020a for elaboration on tripa-rlung imbalances in Tibetan medical perspectives on pathophysiology. 
first take generous amounts of hot, boiled water and hot decoctions to perspire and break the fever. The hot decoctions are from the decoction (thang) class of formulas, known for their swift actions in "ripening" fevers, "gathering" and "expelling" inflammation, and "separating" diseased from healthy blood. ${ }^{98}$ The decoction formulas used for CoviD-19 patients include Manu-4, Norbu-7, Tsowo-8 (Gtso bo), and Trültang ('Phrul thang). Following decoction formulas, several pill formulas provide support for the initial therapeutic stage, including Gurkhyung Pakdor (Gur khyung phag rdor), Pangtsi-12 (Spang rtsi), and Logyönma (Lo gyon ma). These are known to fight infection, support lung function, and strengthen the kidneys and adrenals. ${ }^{99}$

For the subsequent therapeutic phase, each patient must be assessed for the condition's nature specific to symptom presentation as well as progressed disease mode. Some formulas used to address respiratory inflammation specifically have included: Jugang-25, Tsowo-25, Solo-4 (Sro lo), Pangkhyung (Spang khyung), Lotsé Künsel (Glo tshad kun sel), Lukmur-7 (Lug mur), Tsokhyung (Gtso khyung), and Ghitsen (Ghi tsen). These formulas also differentially support gut function, quality blood production, physical strength, and ameliorating inflammation and infection. Each formula is timed particular to individual symptom presentation chronology and pathogenesis of condition. To prevent relapse, the Four Medical Treatises provides the following guidance: "Finally, Gurgum-13, Dejeché, Gabur-25, and so forth limit relapse. Dashel and Nyugu formulations are beyond perfect—-they are auspicious." ${ }^{100}$

\section{Conclusion}

As the Tibetan medical world convened discussions and deliberations worldwide on the advent of SARS-CoV-2's entry onto the global stage, the looming backdrop of prognostications foretold for this degenerate age materialized into lived reality. Compounding causes and conditions of environmental destruction, persistent toxins, and infectious disease synergized into devastating scales of imbalance, unleashing a virulent pathogenic form that ravaged across the world. As life routines were disrupted, deeper levels of societal discord have been unveiled and innumerable persistent local vulnerabilities and hardships have rapidly multiplied to macroscopic scales.

98 Bstan kho 2010, 8.

99 Formula benefits translated from Ri grag 2003.

100 G.yu thog yon tan mgon po 2006, 279. 
In this article, we described SARS-CoV-2 as a type of virulent infection, nyenrim, that is a type of sinbu, or microorganism, innumerable numbers of which comprise and coexist in our very physical form. In balance, these organisms animate, facilitate, and enable our normal daily functions, both in mind and body, producing us as compounded selves of multiplex interdependences. In imbalance, at best, they drive disease, antagonizing the nyépa systems that link our organs, tissues, fluids, and cells; at worst, they threaten to untether our dependent life systems. From the Sowa Rigpa microbiome perspective, our body-mind-environment interrelations precipitate an ecological community inside our body as well as outside. Though nyenrim may not be part of our normal internal microbiome ecology, it is certainly part of our macrobiome-the vast external global biome of organisms of which we are a part. As with any ecological community, nuanced relations and hierarchies maintain structural and functional balances.

Organisms deemed more virulent in certain contexts and conditions provide important services in other more balanced states. For example, Helicobacter pylori, the bacterium known for causing peptic ulcers and driving gastric cancers when in excess in the gut, is a normal part of the gut microbiome in healthy states. ${ }^{101}$ Ecological research shows that parasites and pathogens in internal microecosystems, similar to conserving predators in external macroecosystems, may be as important as symbiotic, commensal, and cohabitant species for sustaining biodiversity resilience. ${ }^{102}$ Such an approach draws upon equilibrium dynamics and stability theory such that "stability increases as population densities move further away from extremely low or high densities." ${ }^{103}$ As our internal ecosystems have changed with major epochs in human history from the founding of agriculture to industrialization and now to extant globalization, the community composition of our microbiome has also changed, altering conditions of varying degrees of suitability for various sinbu types. In Sowa Rigpa, the types and communities of sinbu with which we have populated our body regions also inhibit our nyépa systems in resiliently handling assaults of virulent pathogens such as SARS-CoV-2.

SARS-CoV-2 most severely affects the most vulnerable members of our population - those with compromised immune systems, aged bodies, comorbid complications, and sociostructural disadvantages, marginalizations, and impoverished circumstances. However, even for many mild cases, the disease of CoviD-19 presents as a cascade of systemic effects that blaze with high

\footnotetext{
101 Blaser and Atherton 2004; Talebi Bezmin Abadi 2014.

102 Hudson, Dobson, and Lafferty 2006; Gillespie, Nunn, and Leendertz 2008.

103 McCann 2000, 229.
} 
fevers, piercing headaches, and blunted sensory capacities of gustatory and olfactory perception. From the Sowa Rigpa paradigm, the virus primarily affects rlung-tripa pathways, organs, and functions, demonstrating a primarily inflammatory and neuroendocrine disruptive signature. Prevention, treatment, and recurrent shielding not only require appropriate dietary and lifestyle support, but also the timed administration of systemic- and organ-specific formulas to modulate inflammatory responses and curate immune reactions, as well as strengthen relevant organ functions. However, this virulent infectious disease also requires a particular reorientation of mind-a therapeutically relevant cultivation of awareness and care for the global community of beings in which one resides. It also requires sustained intention to ameliorate the harm waged by voracious greed and resource consumption, further propelled by a rapidly expanding and endlessly interconnected global economy. It incites consideration of how to live with greater balance in relationships that nourish life and well-being. Such cognitive-affective reframing examines the role of afflictive emotions and mental tendencies in spurring behaviors from local to global scales and causing persistent imbalance. It requires reflexivity to reveal the antidote as long-term therapeutic strategy.

At times when such mental orientation is lacking, the Tibetan medical classics remind us that the mamos will continue to be there, prompting us with their fierce methods of causal retribution. The inflicting of raging torments of disease and suffering, and a world blazing with fire externally and internally, is emblematic of their wrath. This wrath reminds us that the basic principles of well-being at individual, communal, and global levels are more pertinent than ever before. Referring to epidemic-level virulent infections, the Four Medical Treatises chapter emphasizes: "Without protection, [they] recklessly develop as if raising their sword and bearing the face of war."104 This passage emphasizes that proper etiological understanding, diagnostic recognition, and treatment armaments are definitive in treating such a tenaciously contagious and relentlessly unforgiving disease. However, it also conveys that it is critical — for both healthcare workers and the public alike - to take valiant measures in inhibiting infection, diminishing its strength immediately if infected, and, even more so, protecting from its recurrence by reversing its socioecological causal conditions. Nyenrim has the capacity to viciously devastate all whom it encounters. As such, it requires a global effort of compassionate wisdom to restore balance in a preciously fragile, intricately interdependent planet.

104 G.yu thog yon tan mgon po 20o6, 279. 


\section{Acknowledgments}

The authors thank John Rawls, director of Duke University's Microbiome Center, for his valuable feedback on the manuscript, and to Tibetan medical colleagues in Tibet, India, North America, and globally for stimulating discussions throughout the COVID-19 pandemic. Tidwell is supported by the Center for Healthy Minds (project number AAG8698), University of Wisconsin-Madison. Research informing this manuscript has been supported by grant MSN248068 from the Foundation for Psychocultural Research, the International Association for the Study of Traditional Asian Medicine, Arizona Friends of Tibet, Kunde Institute, and the Global Health Research Foundation.

\section{About the Authors}

Tawni Tidwell is a Tibetan medical physician and biocultural anthropologist. She completed the Kachupa degree of Tibetan medicine, studying at Men-Tsee-Khang in India and Sorig Loling in Tibet. Currently, she is a postdoctoral research associate with the Center for Healthy Minds, University of Wisconsin-Madison. She also maintains a private clinical practice.

Khenrab Gyamtso is a senior Tibetan medical physician with Menrampa distinction, originally from eastern Tibet. He trained at Men-Tsee-Khang in India, serving as a lecturer and vice principal for eighteen years thereafter. An author and international lecturer, he currently oversees patient care for the Tibetan Traditional Herbal Centre in Toronto, Canada.

\section{Bibliography}

\section{Primary Sources}

Bsam gtan. 2013 [repr. 1985]. Gso rig snying bsdus skya rengs gsar pa. Lhasa: Bod ljongs mi dmangs dpe skrun khang.

Byams pa 'phrin las. 2004. Gso rig lo rgyus. Beijing: Mi rigs dpe skrun khang.

Byams pa 'phrin las. 20o6. Bod lugs gso rig tshig mdzod chen mo. Lhasa: Mi rigs dpe skrun khang.

Dakpo Tashi Namgyal. 2004. Clarifying the Natural State: A Principal Guidance Manual for Mahamudra. Translated by Erik Pema Kunsang and Khenchen Thrangu Rinpoche. Hong Kong: Rangjung Yeshe Publications.

De'u dmar bstan 'dzin phun tshogs. 20o9. Shel gong shel phreng. Beijing: Mi rigs dpe skrun khang. 
Dilgo Khyentse Rinpoche. 1999. Guru Yoga: According to the Preliminary Practice of Longchen Nyingtik. Ithaca, NY: Snow Lion.

G.yu thog yon tan mgon po. 1999. Bdud rtsi snying po yan lag brgyad pa gsang ba man ngag gi rgyud las: Rtsa ba’i rgyud bshad pa'i rgyud phyi ma'i rgyud kha skong dang bcas pa. New Delhi: Men-Tsee-Khang.

G.yu thog yon tan mgon po. 2006. Bdud rtsi snying po yan lag brgyad pa gsang ba man ngag gi rgyud. New Delhi: Men-Tsee-Khang.

G.yu thog yon tan mgon po. Bu don ma. 20o9. Beijing: Mi rigs dpe skrun khang.

Khro ru tshe rnam rin po che. 2003. Gso rig rgyud bzhi'i 'grel chen drang srong zhal lung. Chengdu: Si khron mi rigs dpe skrun khang.

Kong sprul yon tan rgya mtsho. 2005. Gso rig zin tig yang tig. Bod kyi gso ba rig pa'i gna' dpe phogs bsgrigs dpe tshogs 11. Beijing: Mi rigs dpe skrun khang.

Nāgārjuna. 2007. Nagarjuna’s Precious Garland. Translated by Jeffrey Hopkins. Boulder, CO: Snow Lion Publications.

Patrul Rinpoche. 1998. Words of My Perfect Teacher. Walnut Creek, CA: Altamira Press. Pha khol [Vāgbhața]. 2005. Yan lag rgyad pa'isnying po’i bsdus. In Sbyor ba brgya pa dang yan lag brgyad pa'i snying po bsdus pa sogs. Beijing: Mi rigs dpe skrun khang.

Phags pa klu sgrub [Nāgārjuna]. 1989. Sman dpyad zla ba’i rgyal po. Leh: Tashi Yangphel Tashigang.

Ri grag. 2003. Bod kyi gso ba rig pa las sman rdzas sbyor bzo'i lag len gsang sgo 'byed pa'i lde mig. Delhi: Rig Drag Publications.

Sangs rgyas rgya mtsho. 1994. Gso ba rig pa’i bstan bcos sman bla’ dgongs rgyan rgyud bzhi'i gsal byed bai durya sngon po'i malli ka. 2 vols. Dharamsala: Men-Tsee-Khang.

Sangs rgyas rgya mtsho. 2005. Man ngag yon tan rgyud kyi lhan thabs zugs rngu'i tsha gdung sel ba'i katpua, ra dus min 'chi zhags bcod pa'i ral gri. Dharamsala: Men-Tsee-Khang.

Skyem pa tshe dbang. 200o. Rgyud bzhi'i rnam bshad. Xining: Mtsho sngon rigs dpe skrun khang.

Slob dpon pad ma 'byung gnas. 2006. 'Chi med bdud rtsi bum pa. In Slob dpon pad 'byung gi sman yig gces btus. Beijing: Mi rigs dpe skrun khang.

Ston pa shakya thub pa [Śākyamuni]. 20o8. Bka 'gyur gso rig gces btus. Bod kyi gso ba rig pa'i gna' dpe phyogs bsgrigs dpe tshogs, vol. 70. Beijing: Mi rigs dpe skrun khang.

Zur mkhar pa blo gros rgyal po. 1989. Rgyud bzhi'i 'grel pa mes po'i zhal lung. 2 vols. Beijing: Krung go'i pod kyi shes rig dpe skrun khang.

\section{Secondary Sources}

Adarshah 2020. Online Repository of Tibetan Buddhist Scriptures. 17th ed. Gyalwang Karmapa, Ogyen Trinley Dorje, Tsurphu Labrang, Office of H.H. the Karmapa. http://adarsha.dharma-treasure.org/searchword=srin. Accessed February 11, 2020.

Amedei, Amedeo, and Lucia Morbidelli. 2019. "Circulating Metabolites Originating from Gut Microbiota Control Endothelial Cell Function." Molecules 24, no. 21: 3992. 
Bäckhed, Fredrik, Ruth E. Ley, Justin L. Sonnenburg, Daniel A. Peterson, and Jeffrey I. Gordon. 2005. "Host-Bacterial Mutualism in the Human Intestine." Science 307, no. 5717: 1915-20.

Berg, Gabriele, Daria Rybakova, Doreen Fischer, Tomislav Cernava, Marie-Christine Champomier Vergès, Trevor Charles, Xiaoyulong Chen, et al. 2020. "Microbiome Definition Re-Visited: Old Concepts and New Challenges." Microbiome 8, no. 1: 103. Blaser, Martin J., and John C. Atherton. 2004. "Helicobacter pylori Persistence: Biology and Disease." Journal of Clinical Investigation 113, no. 3: 321-33.

Blo bzang don grub and Bkra shis rab brtan. 2020. "Wu'u han nas byung ba'I tog dbyibs nad yams (2019 n-CoV) skor gyi glng slong” [A Brief Discussion on the 2019 n-CoV Coronavirus Epidemic from Wuhan]. Tibet Times, February 12, 2020. https://tibettimes.net/2O2O/O2/12/202374.

Bstan 'dzin dbang phyugs. 2020. "Tog dbyibs nad 'bu [SARS-CoV-2]." Radio Free Asia, Tibetan Language Broadcast Section, January 25, 2020. https://www.rfa.org/tibetan/ society/coronavirus-01252020104626.html.

Bstan kho, ed. 2010. Zhi byed sman sbyor. Beijing: Mi rigs dpe skrun khang.

Can, Ismail, Gulnaz T. Javan, Alexander E. Pozhitkov, and Peter A. Noble. 2014. "Distinctive Thanatomicrobiome Signatures Found in the Blood and Internal Organs of Humans." Journal of Microbiological Methods 106:1-7.

CDCP (Center for Disease Control and Prevention). 2021. "Coronavirus Disease 2019 (COVID-19): People With Certain Medical Conditions." Updated February 22, 2021. https://www.cdc.gov/coronavirus/2019-ncov/need-extra-precautions/people-with -medical-conditions.htmlhttps://www.cdc.gov/coronavirus/2019-ncov/need-extra -precautions/people-with-medical-conditions.html.

Choedon, Tenzin, Dawa Dolma, and Vijay Kumar. 2011. "Pro-Apoptotic and Anticancer Properties of Thapring: A Tibetan Herbal Formulation.” Journal of Ethnopharmacology 137, no. 1: 320-26.

Choedon, Tenzin, Dawa Dolma, Ganeshan Mathan, and Vijay Kumar. 2014. "Molecular Insights into the Anti-Cancer Properties of Traditional Tibetan Medicine Yukyung Karne." BMC Complementary and Alternative Medicine 14: 380.

Choedon, Tenzin, Ganeshan Mathan, Soneera Arya, Vijay L. Kumar, and Vijay Kumar. 2006. "Anticancer and Cytotoxic Properties of the Latex of Calotropis Procera in a Transgenic Mouse Model of Hepatocellular Carcinoma." World Journal of Gastroenterology 12, no. 16: 2517-22.

Claus, Sandrine P., Hervé Guillou, and Sandrine Ellero-Simatos. 2016. "The Gut Microbiota: A Major Player in the Toxicity of Environmental Pollutants?" npj Biofilms and Microbiomes 2, no. 1: 1-11.

Craig, Sienna R., and Vincanne Adams. 2008. "Global Pharma in the Land of Snows: Tibetan Medicines, SARS, and Identity Politics Across Nations." Asian Medicine 4, no. 1: 1-28. 
Craig, Sienna R., and Barbara Gerke. 2016. "Naming and Forgetting: Sowa Rigpa and the Territory of Asian Medical Systems." Medicine Anthropology Theory 3, no. 2: 87-122.

Craig, Sienna R., and Nawang T. Gurung, Ross Perlin, Maya Daurio, Daniel Kaufman, Mark Turin, and Kunchog Tseten. 2021. "Global Pandemic, Translocal Medicine: The COVID-19 Diaries of a Tibetan Physician in New York City." Asian Medicine 16, no. 1: $5^{8-88 .}$

Czaja, Olaf. 2015. "The Administration of Tibetan Precious Pills." Asian Medicine 10, no. $1-2: 36-89$.

Dmig mar che ba. 2020. Bod sman slob gso dang zhib 'jug. Lhasa: Bod ljong bod lugs gso rig slob grwa chen mo.

Dominguez-Bello, Maria Gloria, and Martin J. Blaser. 2011. "The Human Microbiota as a Marker for Migrations of Individuals and Populations." Annual Review of Anthropology 40, no. 1: 451-74.

Drewes, David. 2015. "Oral Texts in Indian Mahayana." Indo-Iranian Journal 58: 117-41.

Exner, Markus, Marianne Raith, Gregor Holzer, Bernhard Gmeiner, Oswald Wagner, and Stylianos Kapiotis. 20o6. "Entzündungshemmende Mechanismen des tibetischen Kräuterpräparats Padma 28 in der Gefäßwand” [Anti-inflammatory Mechanisms of the Tibetan Herbal Preparation Padma 28 in the Vessel Wall]. Forschende Komplementärmedizin 13, suppl.1:13-17.

Fjeld, Heidi E. and Lindskog, Benedikte V. 2017. "Connectedness Through Separation: Human-Nonhuman Relations in Tibet and Mongolia." In Human Nature and Social Life: Perspectives on Extended Sociality, edited by Jon Henrik Ziegler Remme and Kenneth Sillander, 68-82. Cambridge: Cambridge University Press.

Gerke, Barbara. 2010. "Correlating Biomedical and Tibetan Medical Terms in Amchi Medical Practice." In Medicine Between Science and Religion, edited by Vincanne Adams, Sienna R. Craig, and Mona Schrempf, 127-52. New York: Berghahn Books.

Gerke, Barbara. 2020. "Sowa Rigpa in Lockdown: On the Potency and Politics of Prevention." Fieldsights (blog of the Society for Cultural Anthropology), "Hotspots" section, June 23, 2020. https://culanth.org/fieldsights/sowa-rigpa-in -lockdown-on-the-potency-and-politics-of-prevention.

Gerke, Barbara. 2021. Taming the Poisonous: Mercury, Toxicity and Safety in Tibetan Medical Practice. Heidelberg: Heidelberg University Publishing.

Germano, David, and Nicolas Tournadre. 2010. "THL Simplified Phonetic Transcription of Standard Tibetan." The Tibetan and Himalayan Library, February 1, 2020, copyright 2003. http://www.thlib.org/reference/transliteration/\#!essay=/thl/ phonetics/all.

Gilbert, Jack A., Robert A. Quinn, Justine Debelius, Zhenjiang Z. Xu, James Morton, Neha Garg, Janet K. Jansson, Pieter C. Dorrestein, and Rob Knight. 2016. "MicrobiomeWide Association Studies Link Dynamic Microbial Consortia to Disease." Nature 535, no. 7610: 94-103. 
Gillespie, Thomas R., Charles L. Nunn and Favian H. Leendertz. 2008. "Integrative Approaches to the Study of Primate Infectious Disease: Implications for Biodiversity Conservation and Global Health." Yearbook of Physical Anthropology 51: 53-69.

Gu, Silan, Yanfei Chen, Zhengjie Wu, Yunbo Chen, Hainv Gao, Longxian Lv, Feifei Guo, et al. 2020. "Alterations of the Gut Microbiota in Patients with Coronavirus Disease 2019 or H1N1 Influenza." Clinical Infectious Diseases 71, no. 10: 2669-78.

Gyatso, Yonten. 2005-2006. "Nyes pa: A Brief Review of its English Translation." The Tibet Journal 4: 109-18.

Hackett, Paul G. 2013. A Catalogue of the Comparative Kangyur (bka' 'gyur dpe bsdur $m a)$. New York: American Institute of Buddhist Studies.

Harrison, Paul. 1996. "A Brief History of the Tibetan bKa' 'gyur." In Tibetan Literature: Studies in Genre, edited by José Cabezón and Roger R. Jackson, 70-73. Ithaca, NY: Snow Lion.

Heintz-Buschart, Anna, and Paul Wilmes. 2018. "Human Gut Microbiome: Function Matters." Trends in Microbiology 26, no. 7: 563-74.

Hooper, Lora V., Dan R. Littman, and Andrew J. Macpherson. 2012. "Interactions Between the Microbiota and the Immune System." Science 336, no. 6o86: 1268-73.

Hudson, Peter J., Andrew P. Dobson, and Kevin D. Lafferty. 2006. "Is a Healthy Ecosystem One That Is Rich in Parasites?" Trends in Ecological Evolution 21: 381-85.

Ichihashi, Masamitsu, Hiroshi Nagai, and Kayoko Matsunaga. 2004. "Sunlight Is an Important Causative Factor of Recurrent Herpes Simplex.” Cutis 74, no. 5, suppl: $14-18$.

Jankowski, S., A. Jankowski, S. Zielinska, M. Walczuk, and W. J. Brzosko. 1991. "Influence of Padma 28 on the Spontaneous Bactericidal Activity of Blood Serum in Children Suffering from Recurrent Infections of the Respiratory Tract." Phytotherapy Research 5, no. 3: 120-23.

Jenny, Marcel, Wolfgang Schwaiger, David Bernhard, Oliver A. Wrulich, Daria Cosaceanu, Dietmar Fuchs, and Florian Ueberall. 2005. "Apoptosis Induced by the Tibetan Herbal Remedy PADMA 28 in the T Cell-Derived Lymphocytic Leukaemia Cell Line CEM-C7H2." Journal of Carcinogenesis 4: 15 .

Kaliman, Perla, María Jesús Alvarez-López, Marta Cosín-Tomás, Melissa A. Rosenkranz, Antoine Lutz, and Richard J. Davidson. 2014. "Rapid Changes in Histone Deacetylases and Inflammatory Gene Expression in Expert Meditators." Psychoneuroendocrinology 40: 96-107.

Kamada, Nobuhiko, Sang-Uk Seo, Grace Y. Chen, and Gabriel Núñez. 2013. "Role of the Gut Microbiota in Immunity and Inflammatory Disease." Nature Reviews Immunology 13 , no. 5: $321-35$.

Karma 'phrin las, ed. 1993. Lus khams nyi ma'i gnyen po. Lhasa: Bod ljongs mi dmangs dpe skrun khang. 
Korwin-Piotrowska, R., D. Nocon, A. Stankowska-Chomicz, A. Starkiewicz, J. Wojcicki, and L. Samochowiec. 1992. "Experience of Padma 28 in Multiple Sclerosis." Phytotherapy Research 6, no. 3: 133-36.

LeBlanc, Jean Guy, Christian Milani, Graciela Savoy de Giori, Fernando Sesma, Douwe van Sinderen, and Marco Ventura. 2013. "Bacteria as Vitamin Suppliers to Their Host: A Gut Microbiota Perspective." Current Opinion in Biotechnology 24, no. 2: $160-68$.

Lederberg, Joshua. 2001. “'Ome Sweet 'Omics: A Genealogical Treasury of Words.” The Scientist 15, no. 7: 8 .

Lelie, Daniel van der, and Safiyh Taghavi. 2020. "COVID-19 and the Gut Microbiome: More than a Gut Feeling." mSystems 5, no. 4: eoo453-20.

Luo, Hui, Gejia Zhong, Lifeng Yue, Qian Wang, Lina Ma, and Zhaxi Luobu. 2015. "Traditional Tibetan Medicine in China: A Systematic Overview of Randomized Clinical Trials." European Journal of Integrative Medicine 7, no. 5: 450-59.

Lutz, Antoine, Julie Brefczynski-Lewis, Tom Johnstone, and Richard J. Davidson. 2008. "Regulation of the Neural Circuitry of Emotion by Compassion Meditation: Effects of Meditative Expertise." PLoS ONE 3, no. 3: e1897.

MacIntyre, C. Raina, and Abrar Ahmad Chughtai. 2016. "Recurrence and Reinfection: A New Paradigm for the Management of Ebola Virus Disease." International Journal of Infectious Diseases 43: 58-61.

Matijašić, Mario, Tomislav Meštrović, Hana Čipčić Paljetak, Mihaela Perić, Anja Barešić, and Donatella Verbanac. 2020. "Gut Microbiota Beyond Bacteria: Mycobiome, Virome, Archaeome, and Eukaryotic Parasites in IBD." International Journal of Molecular Sciences 21, no. 8: 2668.

Mayer, Emeran A. 2011. "Gut Feelings: The Emerging Biology of Gut-Brain Communication.” Nature Reviews Neuroscience 12, no. 8: 453-66.

Mayer, Emeran A., Kirsten Tillisch, and Arpana Gupta. 2015. "Gut/Brain Axis and the Microbiota." Journal of Clinical Investigation 125, no. 3: 926-38.

McCann, Kevin Shear. 200o. "The Diversity-Stability Debate." Nature 405: 228-33.

mcccc (Microbiome Centers Consortium covid Committee). 2020. "Coordinating and Assisting Research at the SARS-CoV-2/ Microbiome Nexus." mSystems 5: eoog99-20.

McFall-Ngai, Margaret, Michael G. Hadfield, Thomas C. G. Bosch, Hannah V. Carey, Tomislav Domazet-Lošo, Angela E. Douglas, Nicole Dubilier, et al. 2013. "Animals in a Bacterial World, a New Imperative for the Life Sciences." Proceedings of the National Academy of Sciences 110, no. 9: 3229-36.

Melzer, Jörg, Reto Brignoli, Curt Diehm, Jürgen Reichling, Dai-Do Do, and Reinhard Saller. 2006. "Treating Intermittent Claudication with Tibetan Medicine Padma 28: Does It Work?" Atherosclerosis 189, no. 1: 39-46. 
Petersen, Eskild, Marion Koopmans, Unyeong Go, Davidson H. Hamer, Nicola Petrosillo, Francesco Castelli, Merete Storgaard, Sulien Al Khalili, and Lone Simonsen. 2020. "Comparing SARS-CoV-2 with SARS-CoV and Influenza Pandemics." The Lancet Infectious Diseases 20, no. 9: e238-244.

Reuter, K. Philip, Thorolf E. R. Weißhuhn, and Claudia M. Witt. 2013. "Tibetan Medicine: A Systematic Review of the Clinical Research Available in the West." Evidence-Based Complementary and Alternative Medicine 213407.

Rig 'dzin. 2020. “Tog dbyibs nad dug gsar pa'i glo tshad kyi brtag bcos bsam tshul gleng ba" [Brief Thoughts on the Diagnosis and Treatment of Respiratory Inflammation from the New Corona-shaped Pathogen]. Gangs ljongs sman rtsis [Journal of Snowland Medicine and Astro-science] 1: 56-63.

Rosenkranz, Melissa A., Antoine Lutz, David M. Perlman, David R. W. Bachhuber, Brianna S. Schuyler, Donal G. MacCoon, and Richard J. Davidson. 2016. "Reduced Stress and Inflammatory Responsiveness in Experienced Meditators Compared to a Matched Healthy Control Group." Psychoneuroendocrinology 68: 117-25.

Saini, Savita, and Sharad Maroti Porte. 2015. "Ayurvedic Aspect of Bacteria and Bacterial Food Poisoning." International Journal of Pharmaceutical Sciences and Research 3: 2281-9o.

Sangmo, Rigzin, Dawa Dolma, Tenzin Namdul, T. Tsepel, and Ravindra M. Pandey. 2007. "Clinical Trial of Tibetan Medicine in the Treatment of Chronic Hepatitis B." Journal of Men-Tsee-Khang 4, no. 1:32-49.

Sarkar, Amar, Siobhán Harty, Soili M. Lehto, Andrew H. Moeller, Timothy G. Dinan, Robin I. M. Dunbar, John F. Cryan, and Philip W. J. Burnet. 2018. "The Microbiome in Psychology and Cognitive Neuroscience." Trends in Cognitive Sciences 22, no. 7: 611-36.

Schwabl, Herbert, and Jan M. A. van der Valk. 2019. "Challenging the Biomedical Notion of 'Active Substance': The Botanical Plasticity of Tibetan Medical Formulas." HIMALAYA 39, no. 1: 208-18.

Sehnalova, Anna. 2019. "Medicinal Mandala: Potency in Spatiality." HIMALAYA 39, no. 1: $164-88$.

Simioli, Carmen. 2019. "Knowledge, Imagery, and the Treatment of Communicable Disease in the Vase of the Amrta of Immortality: A Preliminary Analysis of a Nyingma Medical Corpus." In Knowledge and Context in Tibetan Medicine, edited by William McGrath, 218-6o. Leiden: Brill.

Sommer, Felix, and Fredrik Bäckhed. 2013. "The Gut Microbiota: Masters of Host Development and Physiology." Nature Reviews Microbiology 11, no. 4: 227-38.

Split, W., M. Szydlowska, and W. J. Brzosko. 1998. "The Estimation of the Action of Padma-28 in the Treatment of Ischaemic Brain Stroke." European Journal of Neurology 5, Suppl. 1: 9 . 
Stargardt, Janice. 200o. Tracing Thoughts Through Things: The Oldest Pali Texts and the Early Buddhist Archaeology of India and Burma. Amsterdam: Royal Netherlands Academy of Arts and Sciences.

Talebi Bezmin Abadi, Amin. 2014. "Helicobacter Pylori: A Beneficial Gastric Pathogen?” Frontiers in Medicine 1: 26.

Tauscher, Helmut. 2015. "Kanjur." In Brill's Encyclopedia of Buddhism, Vol. 1, edited by Jonathan A. Silk, Oskar von Hinüber, and Vincent Eltschinger, 103-11. Leiden: Brill.

Tidwell, Tawni. 2019. "Collapsing Cancer: A Hermeneutical and Praxis-Based Comparative Analysis of Cancer and Tibetan Medical Etiological Categories." In Knowledge and Context in Tibetan Medicine, edited by William McGrath, 140-96. Leiden: Brill.

Tidwell, Tawni. 2020a. "Blood and Chuser across Research Foundations: Constitutive Links in Mapping Biomedical Cancer Maps into Tibetan Medical Nosology." Asian Medicine 15, no. 2: 1-42.

Tidwell, Tawni. 2020b. "COVID-19 and Tibetan Medicine: An Awakening Tradition in a New Era of Global Health Crisis." Fieldsights, "Hotspots," June 9, 2020. https:// culanth.org/fieldsights/COVID-19-and-tibetan-medicine-an-awakening-tradition -in-a-new-era-of-global-health-crisis.

Tidwell, Tawni, and James H. Nettles. 2019. "Conceptions of Potency, Purity, and Synergy-By-Design: Toward Developing a Sowa Rigpa Medical Theory-Based Approach to Pharmaceutical Research." HIMALAYA 39, no. 1: 129-49.

Tidwell, Tawni, Nianggajia, and Heidi Fjeld. Forthcoming. "Chasing Dön Spirits in Tibetan Medical Encounters: Transcultural Affordances and Embodied Psychiatry in Amdo, Qinghai." Transcultural Psychiatry.

Tshul khrims, ed. 2011. gNyan rims gso ba. Beijing: Mi rigs dpe skrun khang.

Vemuri, Ravichandra, Esaki M. Shankar, Marcello Chieppa, Rajaraman Eri, and Kylie Kavanagh. 2020. "Beyond Just Bacteria: Functional Biomes in the Gut Ecosystem Including Virome, Mycobiome, Archaeome and Helminths." Microorganisms 8, no. 4: 483 .

Vennos, Cecile, Jörg Melzer, and Reinhard Saller. 2013. "Clinical Studies on the Efficacy and Safety of Padma 28, a Complex Herbal Formulation from Tibetan Medicine: An Overview." Complementary Medicine Research 20, suppl. 2: 25-30.

Walker, Travis S., Harsh Pal Bais, Erich Grotewold, and Jorge. M. Vivanco. 2003. "Root Exudation and Rhizosphere Biology." Plant Physiology 132, no. 1: 44-51.

Wangchuk, Phurpa, Paul A. Keller, Stephen G. Pyne, Malai Taweechotipatr, Aunchalee Tonsomboon, Roonglawan Rattanajak, and Sumalee Kamchonwongpaisan. 2011. "Evaluation of an Ethnopharmacologically Selected Bhutanese Medicinal Plants for Their Major Classes of Phytochemicals and Biological Activities." Journal of Ethnopharmacology 137, no. 1: 730-42. 
Wangchuk, Phurpa, Paul A. Keller, Stephen G. Pyne, Anthony C. Willis, and Sumalee Kamchonwongpaisan. 2012. "Antimalarial Alkaloids from a Bhutanese Traditional Medicinal Plant Corydalis Dubia." Journal of Ethnopharmacology 143, no. 1: 310-13.

Wangchuk, Phurpa, Paul A. Keller, Stephen G. Pyne, Wilford Lie, Anthony C. Willis, Roonglawan Rattanajak, and Sumalee Kamchonwongpaisan. 2013. "A New Protoberberine Alkaloid from Meconopsis Simplicifolia (D. Don) Walpers with Potent Antimalarial Activity against a Multidrug Resistant Plasmodium Falciparum Strain." Journal of Ethnopharmacology 150, no. 3: 953-59.

Wangchuk, Phurpa, Simon H. Apte, Michael J. Smout, Penny L. Groves, Alex Loukas, and Denise L. Doolan. 2018. "Defined Small Molecules Produced by Himalayan Medicinal Plants Display Immunomodulatory Properties." International Journal of Molecular Sciences 19, no. 11: 349 o.

Whipps, John M., Karen Lewis, and R. Cooke. 1988. "Mycoparasitism and Plant Disease Control." In Fungi in Biological Control Systems, edited by Michael Burge, 161-87. Manchester: Manchester University Press.

Wikoff, William R., Andrew T. Anfora, Jun Liu, Peter G. Schultz, Scott A. Lesley, Eric C. Peters, and Gary Siuzdak. 2009. "Metabolomics Analysis Reveals Large Effects of Gut Microflora on Mammalian Blood Metabolites." Proceedings of the National Academy of Sciences 106, no. 10: 3698-3703.

Wylie, Turrell. 1959. "A Standard System of Tibetan Transcription." Harvard Journal of Asiatic Studies 22: 261-67.

Yum ba. 2020. Gang ljongs sman rtsis. Lhasa: Bod rang skyong ljong 'phrod bsten bde thang u yon lhan khang.

Zhao, Yuhang, Min Wang, Jokyab Tsering, Hanluo Li, Simin Li, Yuepeng Li, Yinghua Liu, and Xianda Hu. 2018. "An Integrated Study on the Antitumor Effect and Mechanism of Triphala Against Gynecological Cancers Based on Network Pharmacological Prediction and In Vitro Experimental Validation." Integrative Cancer Therapies 17, no. 3: 894-901.

Zuo, Tao, Fen Zhang, Grace C. Y. Lui, Yun Kit Yeoh, Amy Y. L. Li, Hui Zhan, Yating Wan, et al. 2020. "Alterations in Gut Microbiota of Patients With COVID-19 During Time of Hospitalization." Gastroenterology 159, no. 3: 944-955.e8.

Zysk, Kenneth G. 1991. Asceticism and Healing in Ancient India: Medicine in the Buddhist Monastery. New York: Oxford University Press.

Zysk, Kenneth G. 1993. Religious Medicine: The History and Evolution of Indian Medicine. New Brunswick, NJ: Transaction Publishers. 